\title{
Procesos de socialización en la transexualidad masculina: una aproximación etnográfica en un espacio asociativo
}

\author{
Elena VAQUERIZO GÓMEZ \\ Universidad Complutense de Madrid \\ elenavaquerizo@ucm.es
}

Recibido: 27-06-2013

Aceptado: 10-04-2014

\begin{abstract}
Resumen:
Este artículo aborda los procesos de socialización/aprendizaje de la transexualidad masculina en una asociación para chicos transexuales. Presenta algunos resultados de una investigación etnográfica de carácter exploratorio, proponiendo como eje analítico la construcción de la subjetividad transexual masculina a través de la socialización entre pares, entendida ésta como “comunidad de práctica” (Lave y Wenger, 1991). Por un lado, se plantean los diversos modos de socialización. Y, dentro de ellos, se establece, primero, la importancia de los roles de los "nuevos"/veteranos en un ámbito no directamente implicado en la producción de subjetividad transexual masculina: la participación en la asociación, pero que aparece también, en segundo lugar, en la construcción de dicha subjetividad, que -dicho sea de paso- no es unívoca (no se da siempre de la misma manera) ni exclusiva (no se activa siempre). Por otro lado, se destacan dos dimensiones de la producción de la subjetividad transexual masculina: el ser y la corporalidad. Estas dimensiones (y la socialización en cada una de ellas) se consideran culturales, por mucho que formen parte de la construcción hegemónica (y, por ello, naturalizada) de la transexualidad; y se presentan como elementos de una "masculinidad subordinada" (Connel, 1997). Ambas dimensiones están asociadas, como se destaca en el artículo, a un interesante mecanismo de socialización: la problematización de situaciones. Por último, se realizan asimismo algunas reflexiones sobre la socialización de madres/padres en la subjetividad transexual. Se concluye con una reflexión sobre la relación entre identidad y subjetividad en el aprendizaje dentro de una comunidad de práctica.
\end{abstract}

Palabras clave: transexualidad, masculinidad, socialización, aprendizaje, subjetividad, identidad, asociaciones 


\title{
Socialization processes in male transsexuality: an ethnographic approach in an associative space
}

\begin{abstract}
This paper is an approach to the processes of socialization/learning within male transsexuality in the context of an association for young male transsexuals. We hereby present some results of an exploratory ethnographic study, establishing as the key axis of our analysis the construction of male transsexual subjectivity within the processes of peer socialization in the sense of "community of practice" (Lave y Wenger, 1991). We start discussing the different forms of socialization focusing first on the importance of the roles of "newcomers" versus veterans within a field that appears on the margins of the production of male transsexual subjectivity, namely the participation in the association. The relationship newcomers/veterans can also be observed within the construction of subjectivity, but is neither unambiguous (it occurs in different ways) nor exclusive (in some cases it is not activated); sometimes the roles and actors may vary. In addition, participation and subjectivity are based on the notion of information as a key category that neutralizes and legitimates the labor of the association. Furthermore, two different forms of transsexual subjectivation processes are headlined, namely the being and the corporealty. These dimensions (and the socialization they include) are considered cultural, nevertheless they are part of the hegemonic (and therefore naturalized) construction of transsexuality. They present themselves as elements of a "subordinated masculinity" (Connel, 1997). Both are remarkably related to a concrete socialization mechanism, namely the problematization of the different situations. The article concludes with some reflections on the socialization of mothers/fathers within the transsexual subjectivity. It concludes with a reflection on the relationship between identity and subjectivity related to learning within a community of practice.
\end{abstract}

Keywords: Transsexuality, masculinity, socialization, learning, subjectivity, identity, associations

\section{Referencia normalizada}

Vaquerizo Gómez, E. (2014). "Procesos de socialización en la transexualidad masculina: una aproximación etnográfica en un espacio asociativo”. Política y Sociedad, Vol 51, Núm. 2: 533-563

Sumario: 1. Antecedentes y objeto de estudio. 2.Metodología. 3.La asociación como espacio de socialización. 4.Ser un chico transexual. 5.Corporalidad transexual masculina. 6.Socialización de madres y padres en la transexualidad masculina. 7.Conclusiones. Bibliografía. 


\section{Antecedentes y objeto de estudio}

En la investigación social de la transexualidad han dominado tres enfoques: sexogénero, medicalización y movimiento asociativo. A continuación realizaré una revisión bibliográfica de estas tres perspectivas, para situar después el enfoque por el que aquí me he decantado en la socialización/aprendizaje; enfoque minoritario en la investigación de la transexualidad pero en continuidad con cierta perspectiva antropológica de la educación en contextos no escolares.

La perspectiva de sexo-género sitúa el foco en la relación de la transexualidad con el sistema sexo-género, en los procesos de feminización/masculinización y de identidad de género, así como en la especificidad experiencial de la transexualidad. Se ha teorizado sobre el carácter transcultural de los "terceros géneros" (Herdt, 1994), pero la transexualidad "occidental" se ha consolidado como temática reveladora de nuestro sistema (binario-normativo) sexo-género, pues -según se planteadepende de él; y con su análisis se ha mostrado el modo en que sexo, género y cuerpo son construidos. Por un lado, encontramos trabajos de corte más teórico (Nieto, 1998; Garaizábal, 1998; Núñez, 2003; Soley-Beltrán, 2009). Por otro, contamos con etnografías sobre los modos en que la experiencia transexual pone en juego sexo y género en diferentes esferas vitales, así como sobre el "tránsito" hacia el sexo/género con el que se autoidentifican los sujetos (para el caso la transexualidad masculina, Cromwell, 1999; Dozier, 2005; para la femenina, Schrock et al., 2005; Mejía, 2006; Vartabedian, 2007; González, 2011; para ambas: CanoCaballero, 2010; Belsué, 2011). Desde este enfoque también se han esclarecido temáticas más específicas: la autoidentificación de la orientación sexual y la insuficiencia de la dicotomía heterosexual/homosexual (Devor, 1993); la reconstrucción biográfica de las experiencias sexuales orientada a una reafirmación de la identidad transexual (Schrock y Reid, 2006); la reproducción de las relaciones asimétricas de género en parejas mujer biológica-varón transexual (Pfeffer, 2010); o el análisis de la discriminación/estigma sociales (Rubio, 2009).

Una segunda línea de investigación se centra en la medicalización y/o patologización de la transexualidad. Se ha enfatizado el papel de las tecnologías/prácticas médicas en la génesis del fenómeno transexual (Hausman, 1998; Billings y Urban, 1998); o la conjunción de los discursos clínico y del derecho en la conformación de la transexualidad como síndrome cultural (Aler Gay, 1992). Desde la psicología social, se han analizado críticamente los discursos patologizantes "psi"/médicos (Martínez-Guzmán e Íñiguez-Rueda, 2010; Roselló, 2013), y en ocasiones, dicho análisis se ha combinado con la perspectiva de las personas transexuales (Mas, 2010; Coll-Planas, 2010), incluso exponiéndose sus narrativas como producciones de conocimientos (situados) que matizan los discursos hegemónicos médico y feminista-queer (Martínez-Guzmán y Montenegro, 2010). Igualmente, se ha propuesto la perspectiva de derechos humanos como alternativa a la patologización (Missé y Coll-Planas, 2010).

Un tercer ámbito de estudio es el movimiento asociativo. El texto de referencia de Ramos (2003) aborda la evolución del movimiento transexual en España desde 
los años 70. Trabajos más recientes dan cuenta de la centralidad de la despatologización como reivindicación principal del movimiento en los últimos años. Así, se ha vinculado la evolución del movimiento trans en España a la de la situación médico-legal (Missé, 2008); se ha analizado el cambio de posiciones/reivindicaciones desde un discurso estratégico de la enfermedad hacia otro centrado en la despatologización (Tena, 2013); se ha conciliado la lucha trans por la despatologización con el feminismo (Biglia y Lloret, 2010). Mención aparte merece el trabajo de Platero (2009), que inserta el movimiento transexual dentro de una perspectiva más amplia de análisis de "marcos interpretativos de política" (que significan la realidad, determinando la comprensión de la misma) que da cuenta de la construcción de los derechos de transexuales como problema público en España.

Existen, por otra parte, estudios difíciles de encuadrar en alguna de las tres perspectivas mencionadas, ya sea porque su objetivo es mostrar la diversidad de perspectivas de los sujetos transexuales, sin que para ello se asuma una orientación teórica definida (Martín, 2004), sea por la especificidad de la población transexual estudiada y el enfoque dado, como el estudio de las condiciones socio-sanitarias de mujeres latinas transexuales que ejercen la prostitución (Amaro, 2010). Y otros trabajos son difícilmente encuadrables porque abren una línea de investigación no continuada posteriormente: es el caso de la propuesta de Irving (2008) sobre la influencia de los factores económicos neoliberales en la configuración del cuerpo transexual como "productivo" y ligado a la clase.

El enfoque que asumo en este artículo, el de la socialización en la transexualidad, también escapa en cierto modo a las tres grandes perspectivas mencionadas. Si bien no ha sido una temática dominante en el estudio de la transexualidad, cabe citar algunos antecedentes. Garfinkel (2006) se refiere al aprendizaje individual (secreto) que Agnes, mujer transexual, emprende sobre las prácticas necesarias para lograr el reconocimiento social de su identidad sexual; un aprendizaje que las mujeres (biológicas) realizan "sin pensar". Muchos de los trabajos de la perspectiva sexo-género podrían leerse asimismo desde este ángulo de aprendizaje individual, pero dicen más sobre el carácter construido del sexo-género y de los dispositivos de tránsito de los transexuales que de la socialización en la transexualidad. Resulta más pertinente situar este artículo en continuidad con las escasas aproximaciones a los aprendizajes colectivos: como el estudio realizado del aprendizaje de recursos narrativos que permiten la construcción biográfica de un "verdadero yo" transexual en un grupo de transexuales (Mason-Schrock, 1996), o el que trata sobre la (trans)formación de la identidad de género en un colectivo de drag kings (Shapiro, 2007). Por otro lado, el énfasis que pondré en la socialización como producción de subjetividad es compartido con los trabajos de Jociles y Charro (2008) sobre la construcción de padres adoptantes/adoptivos en el marco de prácticas socioeducativas institucionales, y de Jociles y Rivas (2009) a propósito de la construcción diferencial de madres solteras por elección según sean adoptivas o utilicen la reproducción asistida. El presente artículo también continúa este interés por las prácticas educativas en contextos no escolares. 
Así, el objeto de estudio son los procesos de socialización en la transexualidad masculina en un contexto asociativo; entendidos estos procesos como prácticas culturales que conforman contextos de construcción de subjetividad. Las características del campo estudiado apuntan a la pertinencia, para su análisis, de la perspectiva de Lave y Wenger (1991), particularmente en lo que se refiere a su concepción del aprendizaje como "participación periférica legítima" en el seno de una "comunidad de práctica”. Ello descentra el aprendizaje de las figuras individuales maestro/aprendiz e implica partir de la práctica de los sujetos, en la que la intencionalidad no tiene por qué ser constitutiva del aprendizaje. Además, el aprendizaje se entiende como un aspecto/dimensión de la práctica, en lugar de que ésta sea subsumida en procesos de aprendizaje, lo cual evita priorizar los procesos cognitivos. Estos autores enfatizan la diversidad de modos de membrecía/participación, estrechamente ligada a los cambios a través del tiempo de las formas de participación y de identidad de los componentes de una comunidad. El presente estudio, por su carácter exploratorio, no alcanza totalmente a describir esta diversidad (diacrónica), aunque sí muestra distintas relaciones de aprendizaje que dependen del aspecto de la socialización (ya sea relativo a la participación en la asociación, ya se trate de alguna dimensión de la subjetividad) que configure el núcleo de ésta. Sin embargo, más bien se pretende apuntar a un diálogo con la vertiente identitaria de la concepción del aprendizaje de Lave y Wenger (1991). Según ellos, en éste acontece siempre una construcción de identidades relacionada con la producción de la comunidad de práctica. Ahora bien, la especificidad de lo que entra en juego en la socialización en la transexualidad (la producción de una subjetividad que adquiere sentido, principalmente, fuera de la propia asociación, pero en el seno de la cual se adquieren ciertas herramientas para gestionar la condición transexual en otros ámbitos vitales) me han llevado al uso de la noción de subjetividad, dejando en suspenso la de identidad. Entiendo por subjetividad el resultado de prácticas/representaciones implicadas en la configuración de un tipo de sujeto mediante la definición, explícita o no, de sus características (qué y cómo es, el modo adecuado de comportarse, etc.); pero es posible que las personas involucradas en esa elaboración del sujeto no se identifiquen (o no lo hagan totalmente) con las características de este último.

Las particularidades del caso estudiado también condicionan el uso de ciertos conceptos de cultura y género. Por un lado, el de cultura como "un proceso reflexivo, un conjunto de convenciones que constituye a los sujetos que lo ponen en práctica, es decir, que da forma a sus acciones y a sus relaciones sociales locales" (Díaz, 2005: 38). Al romper con una noción reificada de cultura, esta definición permite distanciase de una comprensión del aprendizaje como "transmisión/incorporación” de cultura (Díaz, 2005; Jociles y Charro, 2008). Esta reificación se basa, en buena parte, en la metáfora de la cultura como objeto, que contiene una dualidad objeto-sujeto y preconfigura, naturalizándola, la realidad sociocultural (Díaz y Velasco, 1996). En esta línea, la socialización en la subjetividad transexual gana inteligibilidad si se tiene presente la crítica a la disociación de cultura y persona que hacen estos dos autores recién citados: "Al decir que la identidad de los agentes 'es' cultura simplemente queremos señalar que el proceso de construcción 
de las personas (es decir, de los seres socializados) es inseparable del proceso de construcción de relaciones prácticas y simbólicas entre las personas” (Díaz y Velasco, 1996).

Por otro lado, abogo por una perspectiva relacional del género, pues nos encontramos con lo que Connel (1997), a partir de concebirlo como estructurante de prácticas, ha denominado "masculinidad subordinada". En el caso de los chicos transexuales, guarda complejas relaciones con la masculinidad hegemónica debido a la particularidad de la transexualidad de poderse visibilizar u ocultar en función de la situación social. El hecho de que la condición (estigmatizada) transexual pueda ser "invisible" connota a la persona como desacreditable -en lugar de desacreditada-, lo cual requiere controlar la información que se expresa de sí mismo (Goffman, 2010: 61-62). Este doble ángulo (género como estructurante de prácticas y carácter desacreditable de sí frente a otros) encuadra, sin agotarlo, el contexto social de las prácticas implicadas en la configuración de la subjetividad transexual masculina.

\section{Metodología}

En el momento en que se realizó la investigación en que se basa este artículo, la asociación en donde se ha hecho trabajo de campo había sido fundada hacía 8-9 años por un chico transexual que ya no pertenecía a ella y se localizaba/actuaba en una ciudad española. Esta asociación, constituida mayoritariamente por varones transexuales, no cuenta con subvención pública (se autofinancian mediante cuotas de los socios, venta de papeletas, prótesis...) ni con local propio (un Centro de Día les cede una sala para reuniones y actividades eventuales). Sus objetivos oficiales son comunicar, visibilizar e informar. Para ello realizan las siguientes actividades: (i) mensuales: reuniones y fútbol; (ii) anuales: "convivencias" en una casa en las afueras durante 3-5 días, durante las cuales llevan a cabo actividades para "normalizar” la condición transexual (la mayoría coordinadas por los propios socios) y otras de tipo lúdico; (iii) sin regularidad determinada: talleres dirigidos por expertos y charlas (dadas por ellos mismos o también por un experto). No es preciso ser socio para asistir a las actividades, pero serlo conlleva ventajas, como descuentos en las "convivencias" y en las prótesis que revenden (“de paquete” y para orinar). Para poder votar u optar a algún cargo es preciso haber sido socio durante seis meses. La Junta Directiva cuenta con cuatro cargos: presidente, vicepresidente (ocupados exclusivamente por chicos transexuales), secretario y tesorero. Durante la primera mitad de la investigación, estos cargos eran ocupados por Damián, Raúl, Adrián y Oriol; durante la segunda mitad, por Cayetano, Damián, Gloria (chica transexual) y Oriol $^{1}$. Presidente y vicepresidente se ocupan de gran parte de la organización; no

\footnotetext{
${ }^{1}$ Los nombres de los sujetos son ficticios, con el objetivo de preservar su anonimato. Asimismo, se ha evitado, en la medida de lo posible, explicitar el nombre de la asociación.
} 
obstante, los miembros más antiguos de la asociación suelen ayudarles en ello. En este sentido, destacan el papel de Rolando y su pareja Marta, ambos excomponentes de la Junta directiva, y Oriol. El número de personas que participan (socios o no) es variable, pero ronda entre 15 y 20 personas, de las cuales la mayoría son chicos transexuales que se encuentran en distintos momentos del proceso transexualizador ${ }^{2}$ y tienen entre 17 y 40 años. Regularmente asisten también algunos padres/madres y una chica transexual. La participación de los expertos se reduce a eventuales talleres/charlas organizadas por ellos, a veces gratuitamente.

La investigación cualitativa se ha desarrollado desde octubre de 2011 hasta junio de 2012. Al ser exploratoria, no se pretende demostrativa, sino plantear algunas cuestiones/hipótesis. Las técnicas utilizadas han sido observación participante y una entrevista en profundidad. Realicé observación en las actividades regulares (reuniones y fútbol, y sus prolongaciones en un bar), asistí con ellos a las “convivencias”, a dos talleres (uno sobre sexualidad, impartido por una sexóloga/trabajadora social, otro para padres e hijos dirigido por un psicólogo), a una charla de un cirujano plástico y a otra impartida por dos de ellos en unas Jornadas de Universidad. La entrevista se la hice a Rolando, uno de los más veteranos y activos del grupo.

El principal principio metodológico que ha guiado tanto la producción de datos como el análisis ha sido la reflexividad: la interrogación constante de los datos y del modo en que se estaban produciendo, intentando controlar continuamente los conceptos utilizados y evitando proyectar concepciones de sentido común, pues entiendo la producción científica a partir de la jerarquía epistemológica de los actos científicos que plantean Bourdieu, Chamboredon y Passeron, que "subordina la comprobación a la construcción y la construcción a la ruptura [epistemológica]" (2005: 25).

Comenzaré (apartado 3) exponiendo la socialización en la asociación desde el ángulo de la participación, cuya relación con la subjetividad, que se desarrolla en los apartados posteriores, se articula mediante la categoría de "información”. En la participación predomina la relación conflictiva "nuevos miembros"/veteranos. Después abordo la socialización en la transexualidad desde el ángulo de la subjetividad a partir de las dimensiones del ser (apartado 4) y del cuerpo (apartado 5). Se da una activación/desactivación de los roles de participación, relativizándolos y complejizando los aprendizajes. El apartado 6 plantea el papel de padres/madres en la socialización en la transexualidad. Concluiré situando la aportación que hace el

\footnotetext{
${ }^{2}$ El proceso transexualizador se divide en distintas etapas. La primera fase consiste en un número determinado de sesiones con un psicólogo, con la finalidad de obtener el informe en el que conste el diagnóstico. Únicamente en posesión del informe podrá iniciarse la segunda fase, el tratamiento hormonal. Una tercera fase es la operación quirúrgica del pecho ("masculinización del tórax"). Ninguno de los chicos con los que se ha hecho la investigación se han sometido a cirugía genital (faloplastia o metaidoiplastia), pero ésta no es un requisito necesario para realizar el siguiente paso: el cambio de nombre y género en el D.N.I.
} 
trabajo presentado al desarrollo de las grandes temáticas dominantes y al enfoque utilizado de Lave y Wenger (1991).

\section{La asociación como espacio de socialización}

Los objetivos oficiales de la asociación son: establecer herramientas de comunicación entre hombres transexuales (incluido el apoyo emocional), la visibilidad (para sensibilizar/normalizar) y la información (no sólo para los propios chicos sino también para el resto de la sociedad, incluidas las instituciones sanitarias, educativas y los medios de comunicación). Desde el ángulo de la participación, en la asociación se ponen en juego apoyo e información. Su funcionamiento se inserta en dos tensiones constitutivas de la asociación como locus de socialización: entre significados y entre roles de participación. Este carácter constitutivo deriva del problema fundamental de la reproducción/transformación de la comunidad de práctica.

En primer lugar, se produce una tensión entre las significaciones de la asociación. Por un lado, los más veteranos expresan una separación entre el objetivo explícito de la asociación y otros posibles significados. Aunque algunos son considerados ilegítimos (acudir a la asociación a ligar), otros serían legítimos pero quedan fuera del objetivo oficial: "La asociación ofrece apoyo principalmente a los chicos transexuales que están comenzando el proceso, no nos dedicamos a formar activistas. Cada uno luego decidirá si es activista o no, pero ese no es el objetivo de la asociación" (Damián, 32 años, más de 5 años en la asociación). Es más, el activismo supone un modo específico de vivir la asociación que suelen asumir los que llevan más tiempo y que les distingue de aquellos que no han participado nunca en la asociación o cuya participación ha sido puntual: "Hay gente que pasa del movimiento asociativo, hay gente a la que le molesta que les vean con más gente. (...) Luego hay gente que no quiere hacer de la transexualidad toda su vida. (...) De alguna manera el activismo les recuerda una parte de ellos que no quieren que esté ahî" (Rolando, 39 años, más de 5 años en la asociación). En ocasiones, esta disociación entre el objetivo oficial de la asociación y su significación personal de activismo vehicula una expresión de ambivalencia con respecto a quienes acuden únicamente a los encuentros lúdicos:

[Hay] gente que va al fútbol, pero no viene a las reuniones. "No, es que la reunión...”. No, es que la reunión es un coñazo y el fútbol te gusta, tío. Yo, hay gente que no conozco. Me dice Damián "No, no, es que viene al fútbol”. ¡Pero que se pase alguna vez por la reunión! También, mira, si en el fútbol se lo pasan bien, pues tampoco tengo nada que decir. (Entrevista a Rolando, 39 años, más de cinco años en la asociación).

Por otro lado, esta disociación entre objetivo explícito (informar, apoyar) y activismo parece yuxtaponerse a otra tensión que se establece entre la asociación como un espacio-para-otros y como espacio-para-sí. Estos distintos significados de la asocia- 
ción parecen vincularse a los roles de participación en ésta, ya que los "nuevos", especialmente los que acuden por primera vez, suelen hacer un uso de ella que está orientado hacia sí mismos, mientras que la acción de los veteranos se dirige principalmente a atender a las necesidades/preocupaciones de otros (los "nuevos"). No pretendo decir que el simple hecho de ser o identificarse como veterano o "nuevo" sea condición suficiente para la incorporación de uno u otro significado de la asociación, ya que ésta depende también de la función desempeñada por los socios en el espacio asociativo, de los discursos sobre el mismo y de la construcción de sí y del otro (como persona y como persona-en-la-asociación). Por ello, probablemente la tensión para sí/para otros es objeto de diversas modulaciones que impiden establecer una correspondencia unívoca entre cada significado (para sí/para otro) y cada rol ("nuevo"/veterano). Por otra parte, conviene señalar que la separación para sí/para otros no agota la relación entre los "nuevos" y los veteranos. Con todo, a pesar las dos matizaciones mencionadas, cuando la orientación hacia sí es sostenida por los "nuevos" y la orientación hacia otros lo es por los veteranos, los dos significados de la asociación se contraponen de tal manera que permite encuadrar el conflicto entre roles de participación tal y como se manifiesta en este contexto etnográfico.

Un indicio de la asociación como espacio-para-otros está en el hecho de que la categoría "nuevos" es utilizada habitualmente por los veteranos, contrastando con la ausencia de un término específico para calificar a los que llevan más tiempo (yo utilizo "veteranos" para facilitar la lectura); lo cual sugiere la centralidad de los "nuevos". Este espacio-para-otros emerge claramente en los discursos. En el que expongo a continuación se puede ver cómo en él intervienen ciertas concepciones de sí y del otro:

La asociación es un poco el estar ahí. (...) Yo lo pasé tan mal que yo no quiero que nadie se sienta como yo. Yo no quiero que un chaval de diecisiete años se quiera morir como me he querido morir yo. Entonces, en tu mano está eso, el quitar el miedo, el que tengan a alguien para tomar una cerveza. Hay muchísima gente que no tiene vida social, que el único sábado que sale es el que va con [la asociación]. (Entrevista a Rolando, 39 años, más de cinco años en la asociación).

Pero también aparece en las interacciones entre "nuevos" y veteranos; en ocasiones, a través de una relación paternalista. Así, por ejemplo, son habituales las referencias a los "nuevos" como "los/mis niños" o "mis chicos":

Damián dice que al final se anula el Torneo por la lluvia. (...) Añade: "Me parece injusto, íbamos a ganar nosotros, o al menos a conseguir una medalla”. Dice que está enfadado: "Yo quiero una medalla para mis niños". Continúa diciendo que él compra unas medallas y se las da a "sus chicos” el próximo día, que no quiere que se queden sin medalla. (Torneo de fútbol. Damián, 32 años, más de cinco años en la asociación).

Por otra parte, la asociación como espacio-para-sí se vincula a su uso por parte de los "nuevos" para "conocer a gente" (a menudo, "gente como yo") y para "informarse" (sobre el procedimiento para realizar el proceso transexualizador, las técnicas quirúrgicas, los buenos cirujanos...). Estos significados también se dan entre los 
padres/madres que acompañan a sus hijos (aunque el predicado de "nuevos" no se les aplique a ellos): "John, mirando a Orlando y sonriendo, dice que cuando se lo contó a su madre, ella sacó una lista con todos los riesgos. Ángela, mirando a Damián, dice que tenía que estar informada, tanto de lo bueno como de lo malo; y también era importante conocer gente. 'Y aquí estamos', dice mientras sonríe" (Reunión. Ángela, madre de John, menos de un año en la asociación).

En segundo lugar, la tensión entre roles de participación (veteranos/“nuevos”) se vuelve inteligible, por un lado, a la luz de las diversas significaciones de la asociación recién expuestas, y, por otro, a través de la influencia de las trayectorias de participación. Esta última plantea la importancia de la dimensión temporal de los roles (y, por ende, de las significaciones). En efecto, no se debe entender de manera estática la categoría "nuevos", ya que la implicación y el rol en la asociación irán variando en función de las trayectorias de participación. Algunos socios se convertirán en activistas; otros optarán por distanciarse de la asociación o asistir ocasionalmente. No pretendo afirmar que la mayor/menor implicación en la asociación dependa únicamente de las prácticas que en ella se realicen, ya que puede haber múltiples factores externos que influyan en ello (familiares, laborales, trayectorias militantes...). No obstante, parte de la trayectoria hacia la participación plena parece estar relacionada con un cambio explícito en el modo de implicarse en la asociación, y que a ojos de los que llevan más tiempo debe fomentarse en ella:

Rolando dice que es cierto que dentro de la casa los distintos grupos que se hicieron funcionaron muy bien, pero las "convivencias" conllevaban también buscar la casa, comprar la comida, preparar las actividades, etc. Y de eso se ocupan siempre los mismos. Dice que es bueno que "los nuevos" se vayan implicando en las cosas. Marta, elevando el tono de voz, dice: "Es que les tenemos muy mimados. Siempre diciendo ‘ ‘Ay mis niños, ay mis niños!', pero los niños tienen que espabilarse”. (Reunión. Rolando, 39 años. Marta, pareja de Rolando. Ambos, más de 5 años en la asociación).

Las trayectorias de participación vinculadas a un cambio de rol (de "nuevo" a veterano) conlleva una serie de elementos, entre los que cabe destacar: dar charlas, asunción de un papel de orientador/apoyo/informador con respecto a los "nuevos", incremento de responsabilidades (por ejemplo, las ligadas a ocupar un cargo de la Junta Directiva), etc. Sugiero que estos cambios están ligados a un tránsito desde la asociación como espacio-para-sí hacia ésta como espacio-para-otros. No obstante, esta socialización en el rol de veterano, necesaria para la reproducción de la asociación, está en tensión con el objetivo explícito de informar/apoyar, ya que su "éxito" depende de que la participación trascienda el informarse/recibir apoyo.

Ambas tensiones (entre significaciones y entre roles), y su interrelación, manifiestan el desajuste entre el objetivo explícito de informar/apoyar y otros significados/prácticas necesarios para la socialización en el rol del veterano. Ello apunta a una contradicción entre "nuevos"/veteranos en el sentido planteado por Lave y Wenger (1991): la que existe entre continuidad (representada por los veteranos) y el descentramiento vinculado al progresivo acercamiento a la participación plena por parte de los "nuevos", lo cual es una manera de expresar el problema de la repro- 
ducción/transformación de la comunidad de práctica. Dicha contradicción puede ilustrarse con la preocupación de los veteranos por la reducción de la asociación a un punto de información: "Damián me dice que también está preocupado por la asociación (...), que ahora la gente se está yendo, y no sabe qué pasa. Mientras niega con la cabeza me dice que mucha gente viene a por información y cuando la tienen se van, y que lo entiende, pero que le preocupa" (Conversación informal. Damián, 32 años, más de 5 años en la asociación). Esta preocupación está relacionada con el mantenimiento del espacio-para-otros centrado en los "nuevos", pues: "¿Y si luego no se queda nadie a hacerlo...? A los que vengan luego, ¿quién se lo va a contar?” (Entrevista a Rolando, 39 años, más de 5 años en la asociación).

Pero la noción de información trasciende la problemática de la reproducción/transformación de la comunidad, puesto que aunque a lo largo de este apartado ha aparecido inserta en el par información-apoyo, lo cierto es que posee cierta autonomía como categoría estratégica en la construcción de la asociación. Para comprender más profundamente su papel, es preciso situarla en relación con la tesis general planteada en este artículo y que desarrollaré en los dos siguientes apartados: la producción de la subjetividad transexual en el contexto asociativo. Por un lado, como hemos visto, la información constituye un objetivo explícito que atraviesa las tensiones entre significados y roles; desde el ángulo de la participación, es afirmada pero a condición de que (eventualmente) sea "superada" para la reproducción de la asociación, esto es, a condición de que los "nuevos” se involucren en la asociación en un sentido distinto al de informarse y adoptando un rol más activista. Por otro, la información a su vez constituye un mecanismo de neutralización de los procesos de socialización en la transexualidad. Desde este otro ángulo, supone una forma de legitimar la labor de la asociación como un espacio neutral (en el sentido de que no se quiere convencer a nadie de nada): es incondicionalmente afirmada, en tanto que se pretende que sea el fundamento de la asociación y, por ello, a diferencia de lo que ocurre en el ángulo de la participación (en el que su afirmación absoluta supondría un problema para la reproducción de la asociación), debe mantenerse como rasgo definitorio de la asociación sin que sea negada bajo ningún concepto. De este modo, lo que analizo en este artículo como socialización en la transexualidad no es reconocido por los miembros de la asociación como tal, ya que éstos subsumen todos sus componentes en la noción de "información”, neutralizando discursivamente los procesos que contribuyen a producir una subjetividad transexual masculina.

La noción de información parece operar como bisagra entre la socialización en roles de participación y la socialización como producción de subjetividades, uniéndolas sin que deban (con)fundirse analíticamente. Las une no sólo porque, como he indicado, incluye, además de la acción de informar/informarse como un momento de la participación, todos los procesos de socialización en la transexualidad y, de esta manera, no los reconoce como tales, sino también porque fusiona ambos procesos, los de participación y los de socialización en la transexualidad, dentro de una única lógica, la de la participación. Los distintos aspectos de la configuración de la subjetividad transexual masculina -que veremos en los siguientes apartados- como 
son, entre otros, el aprendizaje de la manera adecuada de hablar sobre la transexualidad, la socialización en el cuerpo mediante la percepción visual o la problematización de experiencias vitales, son calificados como formas de informarse y, al mismo tiempo, debido a la capacidad neutralizadora de la noción de información, no se reconocen como prácticas de socialización. Al concebirlos como maneras de informarse y al entender éstas como acciones neutrales, se invisibiliza la socialización en la transexualidad como producción de subjetividad, que no es neutral sino que está configurada por ciertas lógicas socioculturales: se apoya en ciertas representaciones sobre la transexualidad (como algo esencial, naturalizado, pero que conlleva una modificación corporal), en ciertas prácticas educativas (aprendizaje de la importancia de un nombre masculino, problematización de situaciones, etc.), se establecen roles de socialización que no siempre se corresponden con los roles de participación, etc.

Este carácter estratégico de la noción información no es contingente, ya que la transexualidad es ocasionalmente considerada desde fuera como un "capricho", una "elección", un "querer ser" más que lo que ellos mismos reivindican: un ser "desde siempre”. Tachadas de ilegítimas por el colectivo, tales representaciones se contrarrestan neutralizando la labor de la asociación, manteniendo el ser transexual como algo esencial, innato, no aprendido (en cualquier caso, algo que no se juega en el espacio asociativo). Por ello, "dar el paso" (iniciar el proceso transexualizador) se expresa como un acontecimiento individual, en el que no influye la asociación en ningún otro sentido que no sea informar:

A mí la asociación me informó, el paso lo di yo. (...) En la asociación no decimos, y eso lo llevamos un poco a rajatabla, no animamos a la gente: "Hazlo o no hazlo". (...) Yo, bueno, pues he tomado y sigo tomando drogas, fumo, bebo... [Cuando llegué] no tenía veinte años, tenía treinta y cuatro, y yo no sabía lo que me iba a decir el endocrino. Y la asociación a mí lo que me dijo era que daba igual, que yo seguía siendo un tío siempre, me hormonara o no me hormonara, me operara o no. (...) A mí lo que me dijo Oriol fue "Mira, tío, es que es por miedo. Si tienes otras cosas que pensar... Pero por miedo no dejes de hacer nada". Y era eso. Es que la información quita el miedo, es que cuando tú te informas ya te han quitado el miedo. No es que la asociación en sí me quitara el miedo. Me quitó el miedo porque al informarte los miedos se te van. (Entrevista a Rolando, 39 años, más de 5 años en la asociación).

Precisamente esta conexión entre informarse y dar el paso (o saber cómo darlo), que en muchos casos acontece en la asociación, constituye un elemento fundamental de las prácticas culturales productoras de subjetividad transexual. No obstante, antes de abordar la subjetividad, es preciso realizar dos observaciones. Primero: al abordar la elaboración de una subjetividad transexual, no pretendo discutir las hipótesis biomédicas sobre la causa de la transexualidad. Simplemente me centro en algunos procesos que están en la base de cierta manera de expresar dicha subjetividad (no en un sentido meramente discursivo, sino práctico). Segundo: entender esta expresión como cultural significa desnaturalizar las técnicas, prácticas y discursos mediante los que se construye la transexualidad masculina. Así, por ejemplo, aunque las técnicas médicas (hormonación, masculinización del tórax...) y no médicas 
(prótesis, tops...) aparecen como necesarias/naturales en el proceso transexualizador, desde el punto de vista antropológico han de entenderse como recursos culturales, productos históricos y, en este sentido, "historizan" la expresión de la transexuali$\operatorname{dad}^{3}$. Esta historización también se ha realizado para otros fenómenos cuya creación y forma cultural dependen en gran medida del ámbito médico, como es el caso del Trastorno por Déficit de Atención e Hiperactividad (Lakoff, 2000; Singh, 2011).

\section{Ser un chico transexual}

En este apartado y en el siguiente me ocupo de dos dimensiones centrales de la subjetividad transexual masculina, el ser y la corporalidad. Aunque se encuentran vinculadas, las separo analíticamente, dedicando el siguiente apartado al cuerpo, pues éste adquiere una lógica específica muy relacionada con las técnicas corporales. En este apartado, primero delimito relacionalmente el ámbito del ser transexual: lo que no es y lo que sí es. La construcción del ser transexual se basa en una dialéctica entre internalización y externalización del ser (en sentido más abstracto). En segundo lugar, abordo un mecanismo de socialización (las "problematizaciones") que ya no apunta tanto al ser en un sentido abstracto, sino a experiencias vitales.

En un primer nivel, la subjetividad transexual masculina se establece negativamente mediante un distanciamiento con respecto a otros colectivos: travestis, homosexuales, bisexuales y chicas transexuales. Ello no supone la exclusión de la participación en la asociación de personas de esos colectivos; de hecho, algunos de los socios son gays o bisexuales. Más bien supone una definición relacional de la comunidad sobre la base de lo que no se es:

En una conversación sobre que la gente a veces no tenía ni idea de qué es ser transexual, Oriol comenta que algunos te dicen "Pues yo tengo muchos amigos gays”. Y dice: “¿Y a mí qué? Yo no tengo nada que ver con los gays”. Pregunto si no será porque las asociaciones suelen ser LGTB, y él me dice que ese es el problema, que todo está mezclado. (Conversación informal. Oriol, 36 años, más de 5 años en la asociación).

Este distanciamiento respecto a otros colectivos no excluye, sin embargo, la aparición eventual de discursos/prácticas más integradores, explicables por lo que los chicos transexuales tienen en común con otros colectivos, ya sea reivindicaciones comunes a todo el colectivo LGTB (la lucha contra la discriminación) o específicas del colectivo transexual (cobertura pública de las técnicas sanitarias), o bien necesidades vinculadas a la gestión de la vida cotidiana (como ejemplo de ello cabe mencionar la organización por la asociación de un taller de sexualidad dirigido a

\footnotetext{
${ }^{3}$ Encontramos ilustraciones de la desnaturalización/"historización" del fenómeno transexual en trabajos mencionados en el estado de la cuestión y que abordan la transexualidad no como un universal, sino como resultado del conocimiento/prácticas/técnicas médicas.
} 
cualquier persona transexual, independientemente de su género). Pero esto tampoco disminuye la operatividad de las separaciones/distinciones indicadas, puesto que en la comunidad de práctica los chicos se socializan específicamente en el proceso transexualizador masculino.

En un segundo nivel, la subjetividad transexual se construye positivamente, sobre la base de lo que sí es. Encontramos aquí una nueva tensión: entre una internalización y una externalización del ser. Los siguientes extractos del diario de campo pertenecen a una situación social encaminada explícitamente a la "normalización": un coloquio que consistía en resolver las dudas anónimas de los "nuevos":

Damián lee la siguiente pregunta: “¿Cambia tu percepción del mundo o relaciones con otras personas el iniciar el proceso de hormonación y/u operación?”. Oriol: Sí, cambia mucho. Empiezas a confiar en tus amigos, en tu familia, ya no hace falta que estés en tu casa con cara de perro. Yolanda: Te ves en el espejo como eres. Oriol: Hasta que no te operas, no [se refiere a la masculinización del tórax]. Damián: La seguridad... Oriol: Pasas a tener espejos por toda la casa y antes no tenías ninguno. (...) [En un momento posterior, en la misma actividad] Damián: A ver, esta es la última pregunta: "Una persona de chica a chico...”. Oriol interrumpe: Eso está mal dicho. (...) [La persona que ha escrito anónimamente la pregunta, una amiga de uno de los chicos, dice que ha sido ella la que lo ha escrito] Oriol: Es que nunca has sido una chica. (...) Oriol: Cuando te digo que está mal lo de "de chica a chico”, eso está mal porque es importante que ellos cojan esos conceptos, ellos siempre han sido chicos. Damián: Es un puto error de la naturaleza. Oriol: No sabes los conceptos que hay que utilizar para no transmitir cosas erróneas y no puedas salir de ello... (Damián, 32 años, más de 5 años en la asociación y de tratamiento. Oriol, 36 años, más de 5 años en la asociación, y de tratamiento. Yolanda es la pareja de Oriol)

El hecho de que un discurso esencialista ("siempre han sido chicos") y otro más procesual ("hasta que no te operas, no te ves como eres") coexistan en la misma actividad facilita la interpretación. El discurso esencialista se activa como respuesta a la expresión "de chica a chico", por lo que parece una forma de legitimar la condición de ser chico basada en su internalización, independientemente del físico. Aparece en un contexto discursivo en el que la condición de ser (chico) parece cuestionada por una expresión considerada equivocada. Aunque la autora de la expresión equivocada es una mujer no transexual, uno de los veteranos enfatiza la importancia de que "ellos cojan esos conceptos" para no transmitir cosas erróneas. Más allá del cuestionamiento del ser, lo que está en juego es el aprendizaje de un modo adecuado de hablar sobre sí mismo en tanto persona transexual, que concuerda con el énfasis de Lave y Wenger (1991) en el "aprender a hablar" como clave para la participación periférica legítima. Por otro lado, el discurso procesual, que externaliza el ser (chico), plantea una dependencia del ser chico con respecto al físico: la valoración de que te califiquen en masculino sin haber iniciado el cambio físico (“Tú entrabas en una tienda y te dicen: ‘¿Qué quieres, chaval?’, y te engrandeces. Pero ahora es lo que eres". Oriol), o la importancia decisiva de la masculinización del tórax para percibirse a sí mismo como uno es. A diferencia del primero, en este segundo discurso no se alude explícitamente al aprendizaje de los "nuevos". 
Pero, tanto la lógica de la actividad (los veteranos son los que resuelven dudas) como su orientación explícita hacia la normalización de los "nuevos" sugieren su carácter socializador.

Antes de abordar la socialización basada en formas de problematización, debo referirme brevemente a la expresión "normalizar", no sólo porque es la finalidad explícita de la situación social mencionada, sino porque es uno de los objetivos prioritarios de la asociación. En el contexto investigado, tiene dos referentes fundamentales: primero, ciertas actividades ofrecidas por la asociación (talleres, "convivencias”...) orientadas al bienestar de los "nuevos"; segundo, la visibilización pública de la transexualidad (a través de medios de comunicación, eventos...). Desde la perspectiva de este artículo, la diferencia consiste en que la primera forma de normalización conlleva los procesos de socialización que aquí planteo, mientras que la segunda no. Por otro lado, aunque ciertos chicos no tienen problema en visibilizarse mediáticamente, ambas "normalizaciones" pueden llegar a ser contradictorias, pues la visibilidad mediática como colectivo puede plantear a algunos un problema a la invisibilidad individual:

El problema es que la mayoría de nosotros no queremos que en nuestro trabajo u otras personas sepan que somos transexuales, mientras que a las personas que salen en televisión no les importa. Entonces, dan una visión de la transexualidad que no se corresponde con lo que nosotros vivimos. Nosotros preferimos ser invisibles, cuanto más invisibles, mejor. (Taller de sexualidad. Rolando, 39 años, más de 5 años en la asociación y de tratamiento).

El hecho de que los miembros de la asociación consideren necesario "normalizar" su condición transexual sugiere que dicha condición resulta socialmente problemática ya que, de no serlo, no se realizarían actividades para "normalizar" la situación de los "nuevos" ni se daría un conflicto entre visibilidad colectiva e invisibilidad individual. Este carácter socialmente problemático de la transexualidad, o la percepción de ésta como un problema por parte de los chicos transexuales, hace que, desde la perspectiva de la "normalización", la socialización en la transexualidad consista en la producción de una subjetividad cuya expresión práctica convierta la condición transexual en algo aproblemático, ya sea porque es ocultada y/o desconocida por otros, ya sea porque su conocimiento no supone un problema ni para ellos ni para el chico transexual.

El segundo eje de la socialización en el ser consiste en la problematización de situaciones experienciales en las que está en juego ser percibido como un chico (y no como transexual). Destacan tres temáticas. Primero, la ocultación de la condición transexual. Los veteranos suelen dar por sentada la ocultación de la condición transexual en los entornos vitales, realizando abstracción de posibles variaciones en función de los sujetos. Por ejemplo, en las papeletas para un sorteo se evita poner el nombre completo de la asociación (en el que la condición transexual es explícita) y figuran únicamente las siglas, "para no comprometer a nadie", según uno de los veteranos. 
Segundo, la elección del baño público es expresada como un problema por algunos veteranos, hasta tal punto que se plantea la realización de un taller específico para esta y otras cuestiones semejantes:

Damián comenta el siguiente punto del orden del día: los talleres de grupo de apoyo y afrontamiento de conflictos. (...) Sonriendo, dice: "Por ejemplo, a lo mejor vas a un sitio y el baño no tiene puerta. Entonces, ¿qué haces?”. Dice que este tipo de cosas se pueden tratar. Raúl, sonriendo y elevando la voz, dice que si no hay puerta, él se sale y punto: "Entras y vuelves a salir y ya está". Damián se ríe y le dice que entonces se queda sin mear. Raúl sonríe moviendo la cabeza de arriba abajo. Cayetano dice que él se va al baño de tías (Reunión. Damián, 32 años, más de 5 años en la asociación y de tratamiento. Raúl, 30 años, más de un año en la asociación, menos de un año de tratamiento. Cayetano, 30 años, más de un año en la asociación, menos de un año de tratamiento).

La importancia otorgada a dicho problema por el veterano es relativizada por otros chicos que llevan menos tiempo, lo que sugiere la existencia de discontinuidades generacionales en los procesos de socialización. Es posible que haya un desacople entre los problemas percibidos por los veteranos y por los "nuevos" (o menos veteranos), y que tales problemas cambien generacionalmente. Pero también puede suceder que los "nuevos" acaben incorporando las problematizaciones realizadas por los veteranos. Aunque es difícil estimar si tal incorporación se da, encontramos un indicio de ello en el hecho ocasional de compartir experiencias con relación a los baños públicos (convirtiéndolas en acontecimientos) en otras situaciones sociales. Así, durante un torneo de fútbol con otros colectivos LGTB, uno de los chicos transexuales volvió en dos ocasiones de los baños/vestuarios comentando lo que le había sucedido:

Adrián cuenta que casi le echan del vestuario. Cuando estaba entrando en el vestuario de chicos, el conserje le ha dicho "iEh, espera!", y entonces se ha girado y le ha dicho “¿Qué pasa?”, y entonces el hombre le ha dicho “Ah, nada, nada...”, y ya ha entrado en el vestuario. (...) [En un momento posterior] Adrián dice que cada vez que entra en el vestuario le pasa algo, que estaba entrando en el vestuario de los chicos, y otros chicos que iban a entrar también han dicho "Ah, no, que éste es el de niñas”. (Adrián, 24 años, más de un año en la asociación, menos de un año de tratamiento).

Tercero, el ser nombrado de manera adecuada (con un nombre masculino) es prácticamente la primera aproximación a la subjetividad transexual en la asociación, pues surge cuando un chico se presenta a sí mismo por primera vez. La elección de un nombre masculino, ligada a la ocultación del femenino, se considera un aspecto fundamental. La revelación del nombre femenino se problematiza incluso dentro del marco asociativo. En las votaciones de las candidaturas a la Junta Directiva, para las que era necesario mostrar el D.N.I., uno de los veteranos indicó la posibilidad de enseñárselo únicamente a la persona que gestionaba las votaciones. Dijo que no se preocuparan porque no lo vería nadie más y añadió "Sé que no son vuestros nombres, pero hay que hacerlo así”. La importancia del nombre aparece en situaciones 
diversas: las felicitaciones cuando uno consigue cambiarlo en el D.N.I., o el cambio de un nombre masculino provisional a otro después de haberlo pensado mejor; pero su carácter socializante emerge en la sistematicidad con que se le pregunta a los "nuevos" por sus nombres masculinos y, en caso de que no lo tengan, en que se les anime a elegir uno:

Llegan a la sala dos personas, una madre y su hijo. El chico se presenta como Simona. Damián pone cara extrañada y le pregunta “¿Simona? Eso no puede ser”. Damián y Cayetano intercambian miradas. Damián le pregunta al chico si no había pensado un nombre, y él le dice que no, y que no le importaba que le llamaran Simona. (...) [Un rato después, sentados en la mesa para empezar la reunión, Rolando y Damián apuntan los nombres de los asistentes a la reunión, mientras el resto de personas hablan entre sí]. Cuando Rolando le pregunta a Damián el nombre del chico nuevo, Damián le dice que no tiene, que dice que se llama Simona. Rolando le pregunta que, entonces, qué nombre le pone. Entre los dos deciden poner "Ángela y su hijo”. (Ángela y John, 18 años, que acuden por primera vez a la reunión de la asociación. Damián, 32 años, más de 5 años en la asociación y de tratamiento. Rolando, 39 años, más de 5 años en la asociación y de tratamiento).

En el siguiente encuentro, Simona, el protagonista de la anterior cita etnográfica, anunciará su nuevo nombre, John.

\section{Corporalidad transexual masculina}

La experiencia asociativa suele estar vinculada al cambio corporal (“dar el paso”). Algunos chicos aprenden en la asociación el procedimiento para iniciarlo. Otros llegan informados previamente (principalmente vía internet) o bien ya iniciado el proceso (habitualmente en la fase de obtención del informe psicológico), aunque incluso en estos casos aprenden en ella todo tipo de detalles sobre técnicas corporales, cirujanos especializados en transexualidad, etc. Las técnicas utilizadas son tanto médicas (tratamiento hormonal, masculinización del tórax) como no médicas (prótesis, tops). Ninguno de los miembros se ha sometido a ninguna de las cirugías genitales disponibles (faloplastia o metaidoiplastia), alegando que las operaciones no están conseguidas ni son funcionales y "desde la asociación se aconseja que no lo hagan" (entrevista a Rolando). Pero la lógica cultural que modela la socialización en el cuerpo va más allá de la información sobre las distintas facetas del procedimiento mencionadas. La abordaré a través de dos ángulos: primero, a partir de mecanismos de aprendizaje cuyo principal interés radica en que relativizan los roles veteranos/“nuevos”, desactivándolos; segundo, a través de dos técnicas fundamentales de modificación corporal (la masculinización del tórax y las prótesis).

Un primer modo de socialización que relativiza la relación "nuevos”-veteranos está basado en la percepción visual y, en menor medida, táctil. En la asociación se familiarizan con el proceso transexualizador a través de los cambios concretos en los cuerpos de los compañeros. Poder ver estos cambios con los propios ojos y poder hablar sobre ello son aspectos valorados: 
No es lo mismo que alguien te diga "Hormónate” a que llegue un tío que se está hormonando y te diga "Mira, llevo tanto tiempo, estos son los cambios...”. (...) Antonio lleva en su cartera fotos de fotomatón desde antes hasta ahora. Cada año se hace una y, claro, cuando Antonio te saca las fotos y ves cómo se va cambiando, tú sales y dices "Vale”. ¿Sabes?, no es lo que has leído en internet: “Te vuelves loco, efectos secundarios, violencia”. Yo pensé que te pinchabas y te liabas a hostias con todo el mundo. Y es mentira. Yo creo que es uno de los falsos mitos de la testosterona. (Entrevista a Rolando, 39 años, más de 5 años en la asociación y de tratamiento).

Como sugiere la anterior cita, el contacto personal con los cambios corporales posee incluso una función desmitificadora. Un interesante aspecto a investigar serían los imaginarios sobre el cambio corporal que manejan los chicos transexuales previamente a su contacto con la asociación o con otros chicos transexuales y los efectos que este contacto tiene, a su vez, sobre dichos imaginarios, pero no he recogido datos sobre ello ya que no formaba parte de mis objetivos de investigación. Lo que sí puedo destacar es la curiosidad con la que los chicos que no han iniciado el cambio corporal se relacionan con los que sí lo han hecho, especialmente si el compañero se encuentra en una fase inicial del cambio:

Marcos, sonriendo, le pregunta a John si ya nota algo de la hormonación. John sonrí y dice que lo único que nota es que está "salido todo el día”, pero nada más, ni pelos ni nada. Adrián se ríe y dice que él está igual, pero que ya nota los pelos que le van saliendo, le salen granos... Marcos se acerca un poco hacia él y le pregunta si se afeita. Adrián asiente con la cabeza y dice que tiene muy pocos pelitos, pero sí se tiene que afeitar porque en el deporte que practica la gente no lo sabe y que, aunque sean pocos pelos, pinchan y de cerca se ven. Y añade: "Pero mira", mientras se levanta la sudadera, mostrando la barriga y sonriendo. En la barriga tiene bastantes pelos alrededor del ombligo. Marcos exclama “¡Hala!”. Marcos dice que él está deseando empezar a hormonarse y que piensa que le van a salir muchos pelos porque él ya tiene bastantes. Adrián niega con la cabeza y le dice que no tiene por qué, que algunos tenían muchos pelos antes y luego casi no les han salido más. (Conversación informal. Adrián, 24 años, más de un año en la asociación, menos de un año de tratamiento. Marcos, 31 años, menos de un año en la asociación, fase de obtención del informe del psicólogo).

La curiosidad de los que no han iniciado el tratamiento por los primeros efectos en el cuerpo hace que esta socialización sea independiente del tiempo que se lleve en la asociación y, por ende, de los roles "nuevos"/veteranos. En contextos más "íntimos”, mostrar las cicatrices de la masculinización del tórax también es una práctica socializadora. Durante las "convivencias", dos de los chicos mostraron sus cicatrices pectorales a los presentes, combinando el carácter prioritariamente discursivo de la actividad (un coloquio) con este importante componente visual.

Comprobamos así, a propósito de la dimensión corporal, que en ocasiones se difuminan o se trastocan los roles "nuevos"/veteranos que -como se ha indicado en apartados anteriores- parecen predominar en otros contextos. Y, como veremos a continuación, también se relativiza la distinción expertos (médicos)/no expertos (chicos transexuales). Ambas circunstancias apuntan a la idea de Lave y Wenger 
(1991: 93) acerca de que el aprendizaje en una comunidad de práctica no se realiza únicamente entre maestro-aprendiz, sino que puede haber múltiples fuentes de aprendizaje.

El segundo mecanismo de socialización en el cuerpo evidencia mejor estas relativizaciones de roles. Consiste en estrategias de control sobre el cuerpo que, en numerosas ocasiones, se aprenden/enseñan a través de las relaciones entre chicos que se encuentran en fases del proceso y en tiempo de membrecía en la asociación muy similares. Por un lado, hay estrategias orientadas a la obtención del tratamiento hormonal específico deseado:

Marcos le pregunta a Adrián si a él el médico le recetó Testex o primero le dijo Reandron. Adrián dice que al principio le decía que el Reandron era lo mejor, pero que él le dijo que quería Testex. Dice que le dices lo que sea: que se te olvidan las cosas y prefieres que la inyección sea cada menos tiempo, o lo que se te ocurra. Marcos asiente con la cabeza. (Conversación informal. Adrián, 24 años, más de un año en la asociación, menos de un año de tratamiento. Marcos, 31 años, menos de un año en la asociación, fase de obtención del informe del psicólogo).

Por otro lado, hay estrategias que se dirigen al control del cuerpo mediante la autonomía en la inyección del tratamiento hormonal. La valoración positiva de la posibilidad de auto-inyectarse en lugar de tener que acudir a la clínica está emergiendo entre algunos de los chicos que no son de los más "veteranos":

Adrián está diciendo que quiere aprender a ponerse él mismo las inyecciones, para tener autonomía y no tener que ir siempre a la enfermera. John dice que a él también le gustaría ponérselas él mismo. (...) Adrián cuenta que las veces que le han pinchado él le dice a la enfermera que le enseñe, pero la enfermera le dice simplemente que mire. Cuenta que la inyección es en el culo, pero que él podría ponérselas en la pierna, que también se puede. Nos dice que, si no es una enfermera, le gustaría que le enseñara alguien de confianza. (...) Le pregunto si no le puede enseñar alguno de los que llevan tiempo inyectándose, y él me dice que no, porque todos van a que se las ponga una enfermera. (Conversación informal. Adrián, 24 años, más de un año en la asociación, menos de un año de tratamiento. John, 18 años, menos de un año en la asociación, menos de un año de tratamiento).

Este interés en inyectarse de manera autónoma no se da entre los más veteranos. Dada la similitud de edades entre unos y otros, así como la inoperatividad que, en este caso, se descubre en la distinción "nuevos"/veteranos para encontrar el sentido de ese interés diferencial, el factor explicativo podría tener que ver con la "edad hormonal", es decir, el momento en que iniciaron el tratamiento. Al comenzar éste los más veteranos vivieron experiencias percibidas como coercitivas vinculadas al trato que recibieron de los profesionales de la $\mathrm{UTIG}^{4}$, situación que no han vivido

\footnotetext{
${ }^{4}$ La UTIG es la Unidad de Trastornos de Identidad de Género. En el momento en que se redacta este artículo, el nombre de la unidad ha cambiado debido a la modificación de la transexualidad en el
} 
quienes forman parte de una generación "hormonal” posterior. Estas distintas relaciones socio-clínicas al comienzo del tratamiento pueden explicar que quienes vivieron experiencias negativas en la Unidad valoren, principalmente, la autonomía como un trato no coercitivo por parte de los médicos, mientras que entre quienes no han experimentado coerción en sus inicios del tratamiento estén emergiendo otras concepciones de autonomía en el control del cuerpo, como es el caso indicado de la inyección.

Rolando dice que en la UTIG antes era horrible, que les desnudaban y les hacían fotos, que no te dejaban irte de la UTIG. Tenías que firmar un papel que dijera que te comprometías a realizar todo el proceso con ellos, que de ninguna manera te podías ir a un médico privado. Si faltabas uno o dos días a cualquier cita, te echaban de la UTIG. Damián asiente con la cabeza y dice que él se acuerda cuando empezó en la UTIG, que hasta le rompieron los análisis y todo. (Reunión. Rolando, 39 años, más de 5 años en la asociación y de tratamiento. Damián, 32 años, más de 5 años en la asociación y de tratamiento).

Ambas estrategias de control sobre el cuerpo activan una relación de aprendizaje basada en la proximidad generacional en cuanto a la "edad hormonal" y en la autoridad del cambio corporal (el carácter que adquiere el cuerpo como demostrativo de los efectos/modificaciones derivados del tratamiento), relativizando la pertinencia para la socialización en la corporalidad de posiciones sociales no directamente vinculadas al cambio corporal (por ejemplo, los roles de participación). Pero, además, ambas estrategias implican el cuestionamiento de la relación experto/no experto antes sugerido.

Los roles veteranos/“nuevos" vuelven a emerger, sin embargo, en otro tipo de formas de control corporal que, a diferencia de las anteriores, son -cabría decirañadidas y no intrínsecas a la modificación corporal. Es el caso de los consejos sobre hábitos saludables para contrarrestar posibles problemas del tratamiento. A veces se siguen los consejos del veterano, mientras que se desvalorizan los de los médicos. Esto es lo que ocurrió en el torneo de fútbol con otros colectivos LGTB, durante el cual algunos chicos desatendían en tono burlesco los consejos de los médicos, mientras hacían caso a uno de los socios veteranos:

Cayetano, riéndose, comentaba: "Y nosotros aquí, comiendo sal, sin hacer caso a los médicos...”; después, Adrián comentaba que a él le hicieron análisis de calcio y de otras cosas y le dijeron que tenía que adelgazar, que hiciera dieta. Y, a continuación, exclama “¡Sí, dieta!”, levantando el dedo corazón, mientras Cayetano reía. (...) [Al cabo de un rato, después de comer] Cayetano saca de una bolsa varios botes de pastillas y muestra uno en el que pone "Alcachofa". Entonces dice "Hay que comer alcachofa, mucha alcachofaaa”, y añade que es lo que Rolando dice siempre. (Caye-

DSM-V. Puesto que la transexualidad ha dejado de figurar como un trastorno y el nuevo diagnóstico consiste en “disforia de género”, la unidad ahora se llama Unidad de Identidad de Género (UIG). 
tano, 30 años, más de un año en la asociación, menos de un año de tratamiento. Adrián, 24 años, más de un año en la asociación, menos de un año de tratamiento).

Paso ahora al segundo eje de análisis en la socialización en el cuerpo, centrado en la masculinización del tórax y las prótesis. Aquí es preciso tener cuenta la posición de "masculinidad subordinada" (Connel, 1997) de estos chicos pues, junto a otro tipo de prácticas (orinar de pie con prótesis, saludar con la mano, prácticas sexuales mediante la penetración con prótesis...), las dos técnicas mencionadas constituyen estrategias de aproximación a la masculinidad hegemónica.

La “masculinización del tórax” es una expresión utilizada por los veteranos para enfatizar la diferencia con la "mastectomía”, técnica utilizada en mujeres. Aunque en ocasiones también utilicen este último término para referirse a su propia operación, la masculinización del tórax establece una diferencia -técnica y simbólicaentre la operación de las mujeres (quitar pecho) y la suya (reconstruir un pectoral masculino). Cuando en una reunión uno de los chicos se refería a la "mastectomía" que hacía una nueva cirujana, Rolando contestó que "El problema con ella es que no es cirujana plástica, que ella se dedica a hacer mastectomías y las hace muy bien a mujeres, pero para nosotros deja unas cicatrices muy grandes”. Al aprender este tipo de detalles, los chicos suelen volverse verdaderos expertos en técnicas quirúrgicas. Esto les empodera en el trato con los cirujanos, pues poseen un conocimiento que quizá aquellos no les atribuyen y, además, saben qué quieren y qué no. En ocasiones, la instrucción en este tipo de técnicas se expresa como una obligación hacia sí mismos. Adrián me contaba en una conversación informal que había pedido el video de la operación de otro compañero a la ayudante del cirujano, y lo argumentaba como sigue: "Quiero ver la operación para saber todo lo que me van a hacer. Porque, aunque te lo expliquen, no es lo mismo verlo. Sé que hay muchas personas que prefieren no verlo, porque les resulta desagradable. Y a mí tampoco me agrada verlo, pero pienso que tengo que hacerlo".

Por su parte, las prótesis son la técnica corporal no médica por excelencia. A veces los chicos conocen la existencia de estas prótesis en el espacio asociativo, otros las pueden tocar allí por primera vez, cuando se llevan para la venta, pero, además, hay también una instrucción sobre el modo correcto de uso:

Rolando dice que, para ponerse la "prótesis de paquete", tienen que comprar un calzoncillo de doble tela, para poder meterla ahí. Añade que se lava todos los días, como uno se lava a sí mismo. Que tengan cuidado, porque hay quienes se las han dejado olvidadas en los baños de los bares. Marta y Adrián se ríen. Rolando, sonriendo, dice que también tengan cuidado en la piscina, que una vez en unas convivencias había cuatro prótesis flotando. (...) Rolando explica que el freelax [prótesis para orinar] no sirve para los urinarios masculinos, porque hay que inclinarse un poco hacia delante y salpica. (...) Continúa diciendo que lo prueben primero en su casa, que ensayen antes de utilizarlo en un baño público. (Reunión. Rolando, 39 años, más de 5 años en la asociación y de tratamiento).

Además de esta instrucción, la "prótesis de paquete" -término utilizado por elloses significada en la asociación de una manera específica: como disociada/separable 
del cuerpo y como incorporada pero no íntima; significados que son producidos por el tratamiento colectivo dado a las "prótesis de paquete". Ello se explica por el carácter socializador de la asociación, que permite que este tipo de prótesis sean visibles, se hable de ellas con naturalidad $\mathrm{y}$, adicionalmente, se resignifiquen/masculinicen como "penes". Las siguientes citas ilustran las ideas mencionadas:

Cayetano se toca el pantalón, en la zona de los genitales, y mueve las manos como si se estuviera colocando algo. Le dice a Marcos que se ha puesto la prótesis y le dice que la toque. Marcos la toca y se ríe. Cayetano me mira, se ríe, y me pregunta si quiero tocar. Le digo que no hace falta, y ambos nos reímos. (Conversación informal. Cayetano, 30 años, más de un año en la asociación, menos de un año de tratamiento).

[Buscando un balón que se ha perdido] Cayetano coge la mochila de Damián y dice "A ver si va a estar en la mochila el balón". Abre la mochila. Jacinto se ríe y dice "Unos calzoncillos". Cayetano se ríe y dice, señalando la mochila, "Ay va, una polla” y se ríe. (Conversación informal. Cayetano, 30 años, más de un año en la asociación, menos de un año de tratamiento).

El grado de incorporación o el carácter íntimo de las "prótesis de paquete” probablemente dependan de la situación social en la que los chicos las usan o se refieren a ellas, de manera que el modo como se entiende la prótesis varíe y deba ser considerada como una categoría dinámica/variable. En todo caso, tanto las "prótesis de paquete" como las utilizadas para orinar constituyen un tema de conversación habitual, contrastando así con las que sirven para las relaciones sexuales, que se ubican en un ámbito más íntimo (por ejemplo, no se llevan a la asociación y de ellas no se habla tan explícitamente como se hace con los otros dos tipos de prótesis). Pero también se socializa en ellas mediante el mecanismo de problematización al que me referí antes. Los veteranos suelen dar por sentado la conveniencia del uso de prótesis para mantener relaciones sexuales. Así, por ejemplo, durante un taller de sexualidad, las aportaciones que hizo Damián al respecto estuvieron orientadas al uso de estas prótesis, pero después del taller, a solas, me comentó lo siguiente:

Hay chicos que siempre lo hacen con prótesis, pero otros no. Pienso que sobre todo cuando te hormonas y te operas, no necesitas tanto la prótesis, pero creo que a los chicos nuevos les produce más seguridad una prótesis, porque así parece que se sienten más hombres, que no les falta algo. Le pregunto por qué no ha dicho esas cosas en el taller y él me dice que no quiere parecer que va de sobrado y que es superior a los demás. (Conversación informal. Damián, 32 años, más de 5 años en la asociación y de tratamiento).

\section{Socialización de madres y padres en la transexualidad masculina}

Aunque el núcleo de este trabajo es la socialización de los chicos, uno de los ámbitos fundamentales que requiere la aceptación de la condición transexual es el doméstico. Para ello parece conveniente que los familiares y, especialmente, los padres/madres, también sean socializados de modo que se familiaricen con lo que es 
la subjetividad transexual masculina. Ello acontece, para algunos, en las reuniones, para otros, en las actividades específicas para padres, y seguramente buena parte de las veces se produce paulatinamente en el ámbito doméstico. Aquí me centraré en una situación social específica: un taller para padres/madres dirigido por un psicólogo, en el que participaron ocho chicos transexuales de los cuales seis iban sólo con su madre, uno con el padre y la madre y otro con el padre, la madre y el hermano. Su interés radica no sólo en que permite apreciar el rol del experto como docente, sino también en el hecho de que, en el taller, se establecieron relaciones de aprendizaje entre hijos y madres/padres así como entre estos últimos. A pesar de su función de terapia colectiva, que era más bien aparente, lo que estaba en juego era sobre todo la familiarización de los padres/madres con la subjetividad transexual. En cuanto al rol del psicólogo como docente, puede ejemplificarse a través de dos temáticas. Por un lado, la prescripción del modo adecuado de hacer las cosas:

El psicólogo dice que los padres deben seguir el ritmo del hijo, que él es quien tiene que decir cómo quiere que le llamen, porque a veces las cosas llevan su tiempo. Que no le parece bien que los padres lo lleven tan bien al principio y vayan por delante de su hijo, porque todo lleva tiempo. Asimilarlo tiene que llevar su tiempo. Se trata de un proceso y tiene distintas etapas (Taller de padres e hijos).

El contenido de la prescripción no sólo tiene que ver, en este caso, con la formación psicológica del experto sino también con un esquema cultural propio de nuestro contexto sociocultural y, por ello, fuertemente arraigado en nuestro sentido común: la concepción individualizada del proceso de la toma de decisiones. También como parte de un esquema cultural, que cabría calificar de medicalización de la vida cotidiana, puede interpretarse su comentario acerca de que los problemas en las relaciones intrafamiliares "se solucionan con un profesional", no "sentándose en el salón en casa y hablando entre todos", que adquiere sentido en el marco de una sociedad como la nuestra en la que se tiende a medicalizar muchos aspectos de la vida previamente gestionados en otros ámbitos. Ambos esquemas contribuyen a que los padres/madres se familiaricen con una representación específica de la transexualidad: individualizada, generadora de problemas domésticos que requieren terapia...

Por otro lado, el psicólogo ofrece la terminología "adecuada" para la descripción de la transexualidad. Durante la sesión del taller en que se realizó observación participante, explicó la distinción entre orientación sexual ("hacia afuera: quién te gusta") e identidad sexual ("hacia dentro: quién eres tú, cómo te gusta que te llamen, qué es lo que sientes”). El hecho de que esta distinción esté directamente implicada en la elaboración de la subjetividad transexual podría explicar el esfuerzo de padres/madres por utilizarla, así como de las correcciones de los hijos en caso de que aquellos/as se equivoquen:

La madre de Cayetano dice que ella se confundió al principio con eso de "la tendencia”. El psicólogo pregunta: “¿La tendencia?”. Ella mueve el brazo de un lado a otro y dice "Sí, lo de que te gustan las chicas o los chicos". Cayetano, mirando a su madre, dice: "La orientación sexual”. La madre dice "Eso". (Taller de padres e hijos. Su hijo se lo contó hace aproximadamente un año). 
Llama la atención que sean los hijos, y no el psicólogo, los que -en situaciones como la expuesta en la anterior cita- actúan como "educadores". Es más, en la corrección que se expresa en ella no interviene ninguna otra persona que no sea el propio hijo de quien se ha equivocado. En este sentido, cabe hablar de una relación de aprendizaje entre madres/padres e hijos en la que lo que posiblemente está en juego es la aceptación de la condición transexual de estos últimos, pero a través de un intento de incorporación de la subjetividad transexual (en este caso, en lo que se refiere a la terminología adecuada) por parte de las madres/padres. No obstante, este tipo de aprendizaje no aparece cuando el psicólogo introduce o sugiere discursos que no tienen tanto que ver con la subjetividad transexual del hijo sino con la propia percepción de los padres/madres de lo que acontece:

El psicólogo pregunta si no es un poco como si se hubiera muerto alguien. $\mathrm{La}$ madre de Marcos, con la expresión de la cara seria, dice que no, para nada, que para ella no se ha muerto nadie. Mientras, la madre de Cayetano niega con la cabeza. El psicólogo dice que se refiere a que hay una chica que conocía que ahora ya no existe. La madre de Cayetano eleva la voz y dice que es la misma persona, antes chica, ahora chico, pero que es la misma persona, no cambia nada. Ángela, mirando al psicólogo, dice que no es como si alguien se hubiera muerto, que ella no lo expresaría así, sino que es alguien que ha cambiado, ahora esa persona está más feliz, más a gusto, aunque siga siendo la misma persona, pero cambian cosas. El psicólogo eleva algo el tono de voz y dice que es la misma persona pero va a cambiar el cuerpo, y va a ser una persona diferente. (Taller de padres e hijos).

Por último, otras veces son algunas madres/padres quienes enseñan a otras madres/padres. En estos casos el factor explicativo es el tiempo que hace que saben que su hijo es transexual y el grado de aceptación. Lo ejemplificaré a través de las representaciones de la transexualidad como una elección o un "querer ser”. Éstas suponen una amenaza a la esencialización/internalización del ser transexual que realizan los chicos, y su formulación por parte de sus padres resulta problemática para ellos; dándose entre los padres que hace menos tiempo que conocen la situación de su hijo o que "lo llevan peor". En cambio, los que hace más tiempo que lo saben o "lo llevan mejor" esencializan discursivamente la transexualidad. La hipótesis que se puede elaborar a este respecto es que los padres/madres que terminan por compartir la esencialización de la transexualidad han sido partícipes de una socialización en la transexualidad masculina. Este contraste puede verse en las dos siguientes citas:

El padre de Adrián dice que él piensa que es algo "de los tiempos de hoy día", que está todo muy confuso, y luego con el tiempo puede ser que se le pase. (...) El hermano de Adrián, dirigiéndose al psicólogo, dice que eso es lo que le molesta, que ellos [sus padres] piensan que se le va a pasar y que es una elección de Adrián. El padre de Adrián pregunta “¿Una elección?”. El hermano de Adrián dice "Sí, una elección”. El padre de Adrián, elevando la voz, dice "Claro que es una elección". (Taller de padres. Su hijo se lo contó hace aproximadamente dos meses).

Después de que Paca, una de las madres, pregunte si tiene que ver la situación que el hijo ha vivido en casa durante su infancia, la madre de Raúl, negando con la cabeza, dice "No estoy de acuerdo con ella”, puesto que -según dice- eso es algo que 
tienen ellos en la cabeza desde que nacen, desde hace mucho, y que no tiene que ver con nada de cuando eran pequeños. (Taller de padres. Su hijo se lo contó hace más de un año).

Para concluir, sugiero que la emergencia de relaciones de aprendizaje entre padres/madres tiene que ver también con la importancia que tiene la socialización en la transexualidad para la reconstrucción/resignificación de su propia subjetividad como padres/madres de chicos transexuales; por ejemplo, a través de un proceso de reflexividad que implica poner en duda la educación dada a los propios hijos. Éste fue el caso de Paca, que -como se aprecia en la última cita- en el taller preguntó al psicólogo si el hecho de que su hijo fuera transexual podría deberse a "la situación en casa cuando era pequeña”.

\section{Conclusiones}

El estudio de la transexualidad en España ha estado muy vinculado a la (des)patologización y su vínculo con la normatividad del sistema sexo-género. La reciente importancia de la despatologización como reivindicación principal del movimiento transexual quizás ha eclipsado otras posibles líneas de investigación, así como a grupos de transexuales no tan (o no sólo) implicados en el activismo político. La asociación etnografiada en este texto presenta unas características/dinámicas específicas no subsumibles en el tema de la patologización. Los datos aportados apuntan más bien a la necesidad de cuestionar/interrogar algo que muchos trabajos sobre el movimiento asociativo presuponen: la elaboración de una subjetividad transexual en el seno de las asociaciones. Por otro lado, en los estudios desde la perspectiva sexo-género se echa en falta un análisis sobre la influencia de las asociaciones en la configuración colectiva de la masculinización/feminización transexual, quizá debido a que el interés por la construcción social del sexo, género y cuerpo no ha estado unido a la investigación de dinámicas situadas de aprendizaje. El caso aquí estudiado muestra que el trabajo de producción de subjetividad está ligado a trayectorias/roles de participación asociativos, cuya comprensión trasciende (o no se reduce) a la teorización/escenificación de las categorías sexo, género y cuerpo.

Se ha mostrado en el artículo que la relación concreta de aprendizaje depende de la situación social y de lo que está en juego. Los agentes y el carácter de la socialización varían según domine la cuestión de la participación o la de la subjetividad, o según qué aspecto de la subjetividad se esté moldeando, pues incluso personas no directamente implicadas en una subjetividad transexual masculina pueden socializar(se) en ella como padres/madres. Como indiqué en el primer apartado, el carácter exploratorio de la investigación ha limitado el análisis de la diversidad de formas de participación (lo que puede haber generado un excesivo efecto de dicotomización entre "nuevos”/veteranos), así como del proceso de transformación sociocultural (únicamente apuntado por el conflicto de roles o por las diferencias "generaciona- 
les”). No obstante, se han señalado diversas lógicas culturales que modelan los procesos de socialización, ya sea en los modos de participación (como la importancia de la tensión entre el objetivo explícito y otros significados/prácticas, que amenaza la continuidad de la asociación), ya sea en la conformación de una determinada subjetividad (a través de formas definidas de socialización, como ver el cambio corporal o la problematización de situaciones). Además, se ha establecido un mecanismo de integración entre estos dos dominios (participación y subjetividad) sin el cual sus lógicas parecerían autónomas: el papel estratégico de la noción de información.

No obstante, el caso analizado plantea algunas cuestiones relativas al carácter del aprendizaje en una comunidad de práctica cuyo desarrollo podría contribuir a matizar el papel de la persona en dicho aprendizaje. Esta potencialidad del caso investigado deriva de la especificidad de la subjetividad en juego: la transexualidad es una condición vital, implicada/presente en las demás esferas de relación social de la persona. Esta particularidad se expresa también en la idea de normalización, que apunta a un marco sociopolítico que exige un trabajo sobre la subjetividad transexual masculina con el objetivo de convertirla en algo no problemático, es decir, a un contexto sociopolítico (sistema sexo-género, patologización, discriminación...) en el que la persona (varón) transexual deviene desacreditable, con una masculinidad subordinada que prefigura la conveniencia de ocultar la condición transexual. Así, en el caso de la transexualidad, la construcción de la subjetividad en el marco asociativo necesariamente apunta al exterior de la propia comunidad, a las diversas esferas/situaciones vitales de las personas transexuales.

Los resultados de la investigación también señalan la conveniencia de disociar analíticamente identidad y subjetividad, distinción no realizada por Lave y Wenger (1991), quienes únicamente plantean que el aprendizaje implica construcción de identidades. El caso etnográfico analizado en este artículo sugiere que, en efecto, los miembros de la asociación se identifican con alguno de los roles de participación ("nuevos"/veteranos), aunque esta identificación sea cambiante en el tiempo en función de la trayectoria de participación. En este ámbito de participación se produce la construcción de identidades a la que se refieren los autores, en la medida en que ésta se puede constatar en el propio seno de la asociación, que opera como el marco pertinente de activación/incorporación de las identidades basadas en la participación. No obstante, de la producción de una subjetividad transexual en la comunidad de práctica no se puede inferir una construcción de identidad porque, para constatar ésta, habría que salir de la propia comunidad, ya que, en este segundo caso, la identificación con la subjetividad producida en la asociación sólo se puede corroborar en las esferas vitales a las que se encamina dicha subjetividad; dicho de otro modo, no se pueden valorar las identificaciones con una subjetividad que, aunque producida en la comunidad de práctica, adquiere sentido fuera de ella. Así, la reconstrucción de los procesos identitarios de chicos transexuales requeriría un análisis de un material empírico mucho más amplio y diverso (en contextos cotidianos, laborales, familiares...), habida cuenta de la fundamental dimensión relacional de la identidad, que es tanto construida por otros como reivindicada para sí, que 
puede adoptar una forma cultural o comunitaria, así como reflexiva o narrativa biográfica- (Dubar, 2002). En esta línea, sería necesario investigar las diferencias entre una comunidad de práctica, como la estudiada, que produce una subjetividad cuya relevancia se juega principalmente fuera de tal comunidad (por lo que se disocia analíticamente de la identidad), y otra en la que la subjetividad producida está "autocontenida" en la propia comunidad o que se juega en el interior (en la que no se daría esa disociación entre subjetividad e identidad); así como sería necesario investigar si estas diferencias esclarecen la noción de persona en el proceso de aprendizaje.

En definitiva, la concepción de la persona en la teoría de Lave y Wenger (1991: 122) está restringida a la comunidad de práctica, pues aquella es transformada en miembro de una comunidad de práctica (practicante, novato que se vuelve veterano) en tanto desarrolla una identidad en función de sus (cambiantes) conocimientos, destrezas y discursos. En cambio, el caso estudiado complejiza la noción de persona, por cuanto una buena parte de lo que se juega en el aprendizaje trasciende su condición de miembro de una comunidad de práctica; circunstancia que guarda relación con la simultaneidad de los dos tipos de socializaciones (en la participación y en la subjetividad). Además, la producción en la asociación de una subjetividad proyectada hacia ámbitos externos a ella puede interpretarse como un elemento que este tipo de comunidad de práctica tiene en común con la escuela: la "aplicación diferi$d a$ de los saberes en el tiempo y en el espacio” (Díaz de Rada, 2005: 3). Por otro lado, esta peculiaridad apunta no sólo a la distinción entre identidad y subjetividad, sino también a una matización en la fuerza/dirección del aprendizaje. En lugar de reducirse a una fuerza centrípeta (Lave y Wenger, 1991: 100, 122), la participación periférica legítima adquiere también una orientación centrífuga, precisamente debido a la producción de una subjetividad dirigida hacia el exterior, en este caso, de la asociación donde se conforma. Es la dialéctica entre fuerzas (centrípetaparticipación/centrífuga-subjetividad), y no su dicotomización, lo que configura la comunidad de práctica a la vez que localiza su terreno de juego más allá de la misma. 


\section{Bibliografía}

Aler Gay, Isabel. 1992. Del hermetismo en el discurso sobre el género: el transexualismo como síndrome cultural: del sexo generado al género transexuado. Ibáñez Alonso, Jesús (dir.), Universidad Complutense de Madrid, Madrid.

Amaro Quintas, Ángel M. 2010. Triplemente vulnerabilizadas: Vulnerabilidad en la salud, servicios de salud y contextos. Informe cualitativo sobre la prostitución transexual en la ciudad de Alicante. Universidad de Alicante, IUDESP, Vicerrectorado de Investigación. Disponible en web: http://www.iudesp.ua.es/publicaciones [Consulta: 22 de diciembre de 2013]

Belsué Guillormé, Katrina. 2011. "Sexo, género y transexualidad: de los desafíos teóricos a las debilidades de la legislación española”, Acciones e Investigaciones Sociales, 29: 7-32.

Biglia, Bárbara e Imma Lloret. 2010. "Generando géneros y patologizando sujetos”, en Miquel Missé y Gerard Coll-Planas, eds., El género desordenado. Críticas en torno a la patologización de la transexualidad. Madrid: Egales.

Billings, Diwight B. y Thomas Urban. 1998. "La construcción socio-médica de la transexualidad: interpretación y crítica”, en José A. Nieto, comp., Transexualidad, transgenerismo y cultura. Madrid: Talasa.

Bourdieu, Pierre, Jean-Claude Chamboredon y Jean-Claude Passeron. 2005. El oficio de sociólogo. Madrid: Siglo XXI.

Cano-Caballero Gálvez, María D. 2010. La construcción social del cuerpo en personas transexuales. Martín Casares, María Aurelia y Martín de las Heras, Stella (dirs.). Universidad de Granada, Granada.

Coll-Planas, Gerard. 2010. “La policía del género”, en Miquel Missé y Gerard CollPlanas, eds., El género desordenado. Críticas en torno a la patologización de la transexualidad. Madrid: Egales.

Connel, Robert W. 1997. "La organización social de la masculinidad”, en Teresa Valdés y José Olavarría, eds., Masculinidad/es: poder y crisis. Chile: ISIS Internacional (FLACSO).

Cromwell, Jason. 1999. Transmen and FTMs: Identities, bodies, genders and sexualities. Chicago: University of Illinois Press.

Devor, Holly. 1993. "Sexual orientation identities, attractions, and practices of female-to-male transsexuals", The journal of sex research, 30 (4): 303-315. http://dx.doi.org/10.1080/00224499309551717

Díaz de Rada, Ángel. 2005. “¿Qué obstáculos encuentra la etnografía cuando se practica en las instituciones escolares?”, en Actas de la I Reunión Científica Internacional de Etnografía y Educación. Valencia: Germanías: 19-52.

Díaz de Rada, Ángel y Honorio Velasco Maíllo. 1996. "La cultura como objeto”. Signos. Teoría y práctica de la educación, 17. Disponible en web: http://www.quadernsdigitals.net/datos_web/hemeroteca/r_3/nr_45/a_657/657.ht $\mathrm{ml}$ [Consulta: 25 de mayo de 2013] 
Dozier, Raine. 2005. "Beards, breasts, and bodies: doing sex in a gendered world", Gender and society, 19 (3): 297-316. http://dx.doi.org/10.1177/0891243204272153

Dubar, Claude. 2002. La crisis de las identidades: la interpretación de una mutación. Barcelona: Bellatera.

Garaizábal, Cristina. 1998. "La transgresión del género. Transexualidades, un reto apasionante”, en José A. Nieto, comp., Transexualidad, transgenerismo y cultura. Madrid: Talasa.

Garfinkel, Harold. 2006. "El tránsito y la gestión del logro de estatus sexual en una persona intersexuada. Parte 1”, en Harold Garfinkel, Estudios en etnometodología. Barcelona: Anthropos.

Goffman, Erving. 2010. Estigma: la identidad deteriorada. Buenos Aires: Amorrortu.

González Gil, Teresa. 2011. "En busca de la feminidad sentida”: el proceso transexualizador desde la experiencia de las mujeres. Cuidados competentes para favorecer transiciones sanas. Biblioteca Lascasas; 7 (1). Disponible en web: http://www.index-f.com/lascasas/documentos/lc0566.php [Consulta: 22 de Diciembre de 2013]

Hausman, Bernice L. 1998. "En busca de la subjetividad: transexualidad, medicinas y tecnologías de género”, en José A. Nieto, comp., Transexualidad, transgenerismo y cultura: antropología, identidad y género. Madrid: Talasa.

Herdt, Gilbert. (ed.). 1994. Third sex, third gender: beyond sexual dimorphism in culture and history. Nueva York: Zone books.

Irving, Dan. 2008. "Normalized transgressions: Legitimizing the transsexual body as productive", Radical History Review, 100: 38-59. http://dx.doi.org/10.1215/01636545-2007-021

Jociles Rubio, María I. y Cristina Charro Lobato. 2008. “Construcción de los roles paternos en los procesos de adopción internacional: El papel de las instituciones intermediarias”, Política y Sociedad, 45 (2): 105-130.

Jociles Rubio, María I. y Ana M. Rivas. 2009. "Entre el empoderamiento y la vulnerabilidad: la monoparentalidad como proyecto familiar de las MSPE por reproducción asistida y adopción internacional”, Revista de Antropología Social, 18: $127-170$.

Lakoff, Andrew. 2000. “Adaptive will: The evolution of Attention Deficit Disorder”, Journal of the History of the Behavioral Sciences, 36 (2): 149-169. http://dx.doi.org/10.1002/(SICI)1520-6696(200021)36:2\%3C149::AIDJHBS3\%3E3.0.CO;2-9

Lave, Jean y Etienne Wenger. 1991. Situated learning. Legitimate peripheral participation. New York: Cambridge University Press.

Núñez, Esther. 2003. "La transexualidad en el sistema de géneros contemporáneo: del problema de género a la solución del mercado", en Raquel Osborne y Óscar Guasch, comps., Sociología de la sexualidad. Madrid: Siglo XXI. 
Martín Romero, Dolores. 2004. La transexualidad, diversidad de una realidad. Cuadernos Técnicos de Servicios Sociales. Madrid: Consejería de Familia y Asuntos Sociales.

Martínez-Guzmán, Antar y Lupicinio Íñiguez Rueda. 2010. "La fabricación del Trastorno de Identidad Sexual: Estrategias discursivas en la patologización de la transexualidad", Discurso y Sociedad, 4 (1): 30-51.

Martínez-Guzmán, Antar y Marisela Montenegro. 2010. "Narrativas en torno al Trastorno de Identidad Sexual: De la multiplicidad transgénero a la producción de trans-conocimientos”, Prismasocial, Revista de Ciencias Sociales, 4.

Mas Grau, Jordi. 2010. Identidades gestionadas: un estudio sobre la patologización y la medicalización de la transexualidad. Disponible en web: http://diposit.ub.edu/dspace/bitstream/2445/17986/1/Tesina\%20Jordi\%20Mas.p df [Consulta: 20 de noviembre de 2011]

Mason-Schrock, Douglas. 1996. 'Transsexuals' narrative construction of the 'true self'”, Social Psychology Quarterly, 59 (3): 176-192. http://dx.doi.org/10.2307/2787018

Mejía, Norma. 2006. Transgenerismos: una experiencia transexual desde la perspectiva antropológica. Barcelona: Bellaterra.

Missé, Miquel. 2008. "Argumentos para la descatalogación del trastorno de identidad de género. Situación médico-legal y movimiento trans en el Estado español”. Boletín T-Informa del Secretariado Trans de ILGA, 10. Disponible en web: http://trans_esp.ilga.org/trans/bienvenidos_a_la_secretaria_trans_de_ilga/bibliot eca/articulos/argumentos_para_la_descatalogacion_del_trastorno_de_identidad_ de_genero_situacion_medico_legal_y_movimiento_trans_en_el_estado_espanol 1 [Consulta: 22 de diciembre de 2013]

Missé, Miquel y Gerard Coll-Planas. 2010. "La patologización de la transexualidad: reflexiones críticas y propuestas”. Norte de Salud Mental, VIII (38): 44-55.

Nieto, José A. 1998. "Transgénero/Transexualidad: de la crisis a la reafirmación del deseo”, en José A. Nieto, comp., Transexualidad, transgenerismo y cultura. Antropología, identidad y género. Madrid: Talasa.

Pfeffer, Carla A. 2010. “'Women's work'? Women partners of transgender men doing housework and emotion work", Journal of Marriage and Family, 72 (1): 165-183. http://dx.doi.org/10.1111/j.1741-3737.2009.00690.x

Platero Méndez, Raquel. 2009. “Transexualidad y agenda política: una historia de (dis)continuidades y patologización”, Política y Sociedad, 46 (1 y 2): 107-128.

Ramos Cantó, Juana. 2003. "Las Asociaciones de Transexuales”, en Antonio Becerra Fernández, comp., Transexualidad. La búsqueda de una identidad. Madrid: Díaz de Santos.

Roselló Peñaloza, Miguel. 2013. "Entre cuerpos inacabados e identidades imposibles: la (psico)patologización de la transexualidad en el discurso psiquiátrico", Quaderns de Psicología, 15 (1): 57-67.

Rubio Arribas, Francisco J. 2009. "Aspectos sociológicos de la transexualidad”, Nómadas. Revista Crítica de Ciencias Sociales y Jurídicas, 21. 
Shapiro, Eve. 2007. "Drag kinging and the transformation of gender identities", $\begin{array}{lllll}\text { Gender and } 21 \text { (2): } & \end{array}$ http://dx.doi.org/10.1177/0891243206294509

Schrock, Douglas, Lori Reid y Emily M. Boyd. 2005. “Transsexuals' embodiment of womanhood”, Gender and society, 19 (3): 317-335. http://dx.doi.org/10.1177/0891243204273496

Schrock, Douglas y Lori Reid. 2006. “Transsexuals' Sexual Stories”, Archives of Sexual Behavior, 35 (1): 75-86. http://dx.doi.org/10.1007/s10508-006-8996-8

Singh, Ilina. 2011. "A disorder of anger and aggression: Children's perspectives on attention deficit/hyperactivity disorder in the UK”, Social Science \& Medicine, 73: 889-896. http://dx.doi.org/10.1016/j.socscimed.2011.03.049

Soley-Beltrán, Patricia. 2009. Transexualidad y la matriz heterosexual: un estudio crítico de Judith Butler. Barcelona: Bellaterra.

Tena, Fernando. 2013. "Sacudirse la tutela médica. Hacia la despatologización de la transexualidad”, Revista Andaluza de Antropología, 5: 35-65.

Vartabedian, Julieta. 2007. "El cuerpo como espejo de las construcciones de género. Una aproximación a la transexualidad femenina”. Quaderns-e de l'ICA, 10. 